NASA Technical Memorandum 85902

\title{
Preliminary Flight Test Results of the F100 EMD Engine in an F-15 Airplane
}

Lawrence P. Myers and Frank W. Burcham, Jr.

Juiv $1: 1984$

LANGLEY RESEARCH CENTER

LIBRARY, NASA

HAMPTON, VIRGINIA' 
NÁSA Technical Memorandum 85902

\section{Preliminary Flight Test Results of the F100 EMD Engine in an F-15 Airplane}

Lawrence P. Myers and Frank W. Burcham, Jr.

Ames Research Center, Dryden Flight Research Facility, Edwards, California 93523

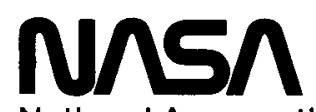

National Aeronautics and

Space Administration

Ames Research Center

Dryden Flight Research Facility

Edwards, California 93523 
6

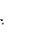


PRELIMINARY FLIGHT TEST RESULTS OF THE F100 EMD ENGINE IN AN F-15 AIRPLANE

\author{
Lawrence P. Myers* and Frank W. Burcham, Jr. \\ NASA Ames Research Center \\ Dryden Flight Research Facility \\ Edwards, California
}

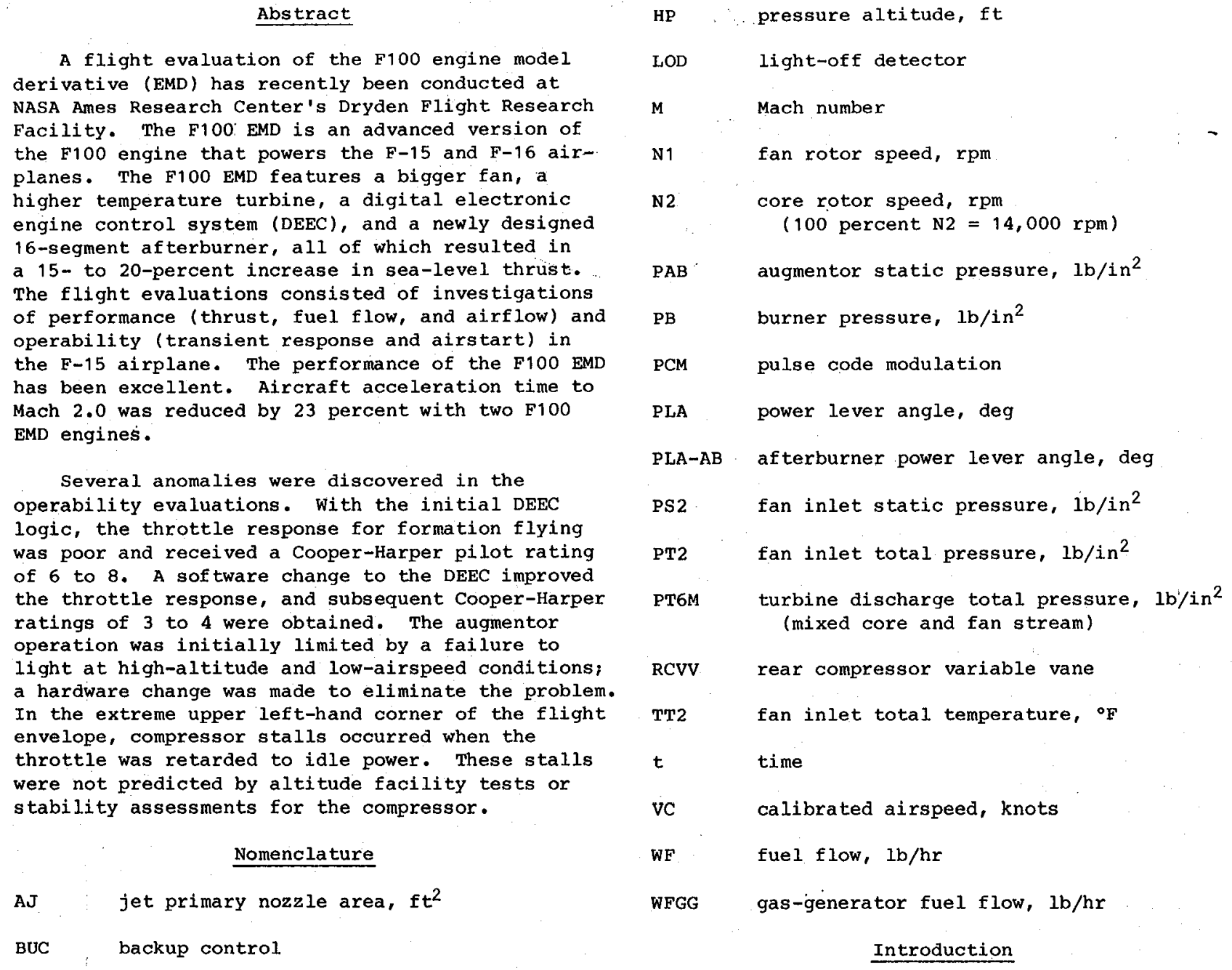

CENC : convergent exhaust nozzle control

CIVV compressor inlet variable vane

DEEC digital electronic engine control

EMD engine model derivative

EPR engine pressure ratio, PT6M/PT2

FA-AB afterburner fuel air ratio

FTr : fan turbine inlet temperature, ${ }^{\circ} \mathrm{F}$

GG gas generator

HIDEC : highly integrated digital electronic control

*Aerospace Engineer. Member AIAA.

*Chief, Propulsion Section. Member AIAA.

This paper is declared a work of the U.S.

Government and therefore is in the public domain.
In the development of new or modified engines, it is important to conduct flight tests as soon as a flyable engine is available. performance and operability flight tests can often reveal problems that were not anticipated, and reveal them early enough in the development cycle to make cost-effective and timely improvements. Recently, a flight evaluation of a digital electronic engine control (DEEC) on an F100 engine was accomplished in an F-15 airplane at NASA Ames Research Center's Dryden Flight Research Facility.l In the first and second phases, significant problems were found; these problems were solved by the fourth phase, resulting in major improvements to the operation of the engine. Currently, a flight evaluation of the F100 engine model derivative (EMD) engine is being conducted in an F-15 airplane at Ames Dryden. The F100 EMD is a derivative of the F100-PW-100 engine. Performance improvements include a higher airflow fan and increased temperature turbine, resulting in 15 to 20 percent more thrust at sea level. The F100 EMD engine is also equipped with a DEEC and a 16-segment augmentor which results in improved 
augmentor operation at high altitude and low airspeed. Performance evaluations consisted of intermediate and maximum power aircraft accelerations at altitudes from 5,000 to $40,000 \mathrm{ft}$. Operability studies included nonaugmented and augmented throttle transients, airstarts, and formation flying. Several anomalies were discovered during the flight test program and are discussed in this paper.

\section{Airplane Description}

The F-15 airplane is a high-performance, twinengine fighter, capable of speeds to Mach 2.5. It has a high-mounted sweptback wing, twin vertical stabilizers, and a horizontal stabilator (Fig. 1). The engine inlets are of two-dimensional horizontal ramp design. The inlets use external compression with three ramps, and feature variable capture area by rotating the inlet about a transverse hinge point at the lower cowl lip. The ramps and bypass door are automatically scheduled by the air inlet controller.

\section{Engine Description}

The F100 EMD engine (company designation PW1128); shown in Fig. 2, is a low-bypass ratio (0.65), twin spool, af texburning turbofan, derived from the F100-PW-100 engine. The three-stage fan is a new design, and has a 6-percent increase in äirflow to $248 \mathrm{lb} / \mathrm{sec}$, a 7-percent increase in pressure ratio and a 3.5-percent increase in efficlency over a standard F100 engine. The fan is driven by ${ }^{\circ}$ a two-stage, low-pressure turbine. The 10-stage, high-pressure compressor is driven by a two-stage, high-pressure turbine. The engine incorporates compressor inlet variable vanes (CIVV) and rear compressor variable vanes (RCVV) to achieve high performance over a wide range of power settings; a compressor bleed is used only for starting. Continuously variable thrust augmentation is provided by a mixed-flow afterburner, which is exhausted through a variable area convergentdivergent nozzle. The augmentor has nine fixed orifice spray rings (shown in the inset of Fig. 2) which are sequenced as 16 discrete segments. Because each of the 16 'segments has a small volume, the pressure pulses created by sequencing between segments are small, and the need for a "quick fill" system (such as on the F100-PW-100 engine) is eliminated. An ultraviolet light-off detector (LOD) is installed to send a signal to the engine control system that indicates that the augmentor is lit.

The prototype F100 EMD engines flown in this evaluation were serial numbers 680350 and 680585 .

\section{Engine Control System}

The digital electronic engine control (DEEC) ${ }^{2}$, is a full-authority, engine-mounted, fuel-cooled digital electronic control system that performs the functions of the standard F100 engine hydromechanical, unified fuel control and the supervisory digital electronic engine control. The DEEC consists of a single-channel digital controller with selective input-output redundancy, and a simple hydromechanical backup control (BUC).

The DEEC system is functionally illustrated in Fig. 3. It receives inputs from the airframe through power lever angle (PLA) and Mach number (M).
Inputs from the engine are received through pressure sensors (PS2, PB, and PT6M), temperature sensors. (TT2 and FTIT), rotor speed sensors (N1 and N2), and the ultraviolet light-off detector (LOD). The DEEC system aiso receives feedbacks from the controlled variables through position feedback transducers indicating variable vane (CIVV and RCVV) positions, metering valve positions for gas-generator fuel flow (WFGG), augmentor fuel flow, segment sequence valve position, and exhaust nozzle position (AJ). Dual sensors and position transducers are used as shown in Fig". 3 to achieve redundancy in key parameters.

The input information is processed by the DEEC computer to schedule the variable vanes (CIVV and RCVV), to position the compressor start bleeds, to control gas-generator and augmentor fuel flows, to position the augmentor segment-sequence valve, and to control exhaust nozzle area.

\section{DEEC Logic}

The DEEC logic provides open-loop scheduling of CIVV, RCVV, start bleed position, and augmentor controls. The DEEC incorporates closed-loop control logic for control of WFGG and AJ. With this closed-loop logic, it is possible to eliminate the need for periodic trimming and to improve performance. The two closed loops are shown in Fig. 4. The top part of the figure shows the total airflow logic in which WFG is controlled to maintain the scheduled fan speed and hence, airflow. Proportional-plus-integral control is used to match the fan rotor speed (N1) request to the sensed $N 1$. Limits of core rotor speed (N2), fan turbine inlet temperature (FTIT), and burner pressure (PB) are maintained. The airflow loop is used for all throttle settings.

The lower part of Fig. 4 shows the engine pressure ratio (EPR) loop. The requested EPR is compared with the EPR, based on fan inlet total temperature (PT2) and turbine discharge total pressure (PT6M) and, using proportional-plus-integral control, the nozzle is modulated to achieve the requested EPR. The EPR control loop is only active for intermediate power operation and augmentation. At lower power settings, a scheduled nozzle area is used.

With the closed-loop airflow and EPR logic, the DEEC control is capable of automatically compensating for engine degradation. EPR is directly related to thrust, so the DEEC can maintain an engine at a desired thrust level. As the engine degrades, the FTIT required to achieve the scheduled EPR will increase until it reaches its limit. The DEEC will then operate the engine on the FTIT limit.

The PT2 signal is derived from the fan inlet static pressure (PS2) measurement. A PT2 to PS2 relationship has been determined from previous wind tunnel and flight tests. ${ }^{3}$

\section{Augmentor Logic}

Augmentor fuel distribution is handled by a segment-seqencing valve. The sequencing valve supplies metered flow to each of 16 segments. A single metering valve with 16 individual ports is used to meter fuel flow. The pressure drop across each metering port is regulated by individual 
proportional pressure-regulating valves. The metered fuel flow passes through the hydraulically operated shutoff valve and is manifolded to the spray rings. The spray rings are equipped with fixed orifices to spray the fuel into the airstream. Each segment is turned on and off sequentially by the segment selector valve. The maximum number of segments that are allowed varies with flight condition; at low values of PT2, the latter segments are not used in order to prevent augmentor rumble.

\section{Airstart Logic}

The DEEC incorporates closed-loop logic for airstarts. A scheduled value of high rotor speed acceleration is compared to the actual value and the gas-generator fuel flow is modulated to maintain the scheduled value. This closed-loop feature reduces the possibility of hot starts or hung starts and permits successful airstarts at lower airspeeds. Details of the airstart logic are given in Ref. 4.

Two DEEC software logic packages were flown. For the first series of flights, DEEC logic 4.2 .1 was flown, while for the second series of flights, modifications were incorporated into DEEC logic 4.2 .2 .

\section{Backup Control (BUC)}

The backup control in the DEEC system is a simple hydromechanical engine control housed in the same unit as the DEEC gas-generator fuelmetering valves. BUC operation is limited to nonaugmented power and is operable, at a reduced performance level, over the entire engine operating envelope. Additional information on the BUC is given in Ref. 5.

\section{Data Acquisition and Reduction}

Pressures, temperatures, rotor speeds, fuel flows, and positions were measured by independent instrumentation on the DEEC test engine. A total of 42 fan inlet total pressure (PT2) measurements were made with probes that were installed in the inlet guide vanes. In addition, a 100-word, serial, digital data stream from the DEEC computer was recorded. Angles of attack and sideslip, noseboom total and static pressures, and other aircraft parameters were measured. Data were recorded on a pulse code modulation (PCM) system. High-frequency response parameters, such as $\mathrm{PB}, \mathrm{PAB}, \mathrm{PT} 2$, and the augmentor segment fue1 pressures, were recorded at 200 samples/sec; the other engine and aircraft parameters were recorded at 20 samples/sec. The DEEC digital data was updated at 5 samples/sec. The data were recorded on a tape recorder on the F-15 and were also telemetered to the ground for recording and real-time analysis and display. More information on the data system is given in Ref. 6 .

\section{Tests And Procedures}

The F100 EMD flight evaluation consisted of 17 flights, for a total flight time of $21.8 \mathrm{hr}$. Included were 298 augmentor transients, 101 airstarts, more than 87 nonaugmented transients, backup control system evaluations, maneuvering flights, accelerations, and climbs. A maximum Mach number of 2.0 was reached and a minimum airspeed of 99 knots at an altitude of 25,000 ft was achieved. Test points were flown up to 50,000 ft to evaluate the augmentor operation.

For those points in which stabilized speed and altitude were required, the pilot used the right engine to control speed while the left engine was evaluated. In maneuvering flight, large angles of attack and sideslip (up to about $25^{\circ}$ and $15^{\circ}$, respectively) were flown, and throttle transients were performed. Ref. 7 describes the test procedures in more detail.

There were two basic types of throttle transients: throttle snaps and throttle bodies. A throttle snap is a rapid single-direction movement from one stabilized power setting to another. The throttle bodie begins with a snap in one direction followed closely by a snap in the other direction before stabilization.

For augmented transients, a series consisted of an intermediate-to-maximum-to-intermediate throttle sequence, followed by idle-to-maximum-toidle snaps. When stalls or blowouts occurred at a given test point, the transient was repeated until the same result was achieved in two out of three trials.

For airstarts, the pilot set up at the desired test condition, advanced the throttle to intermediate power to provide repeatable initial conditions, and then shut down the engine. As the engine spooled down to the desired N2 speed, the pilot moved the throttle to idle to initiate the airstart. Speed and altitude were maintained by using the right engine until the test engine reached idle rpm, or until an unsuccessful airstart was evident. Unsuccessful airstarts were indicated by either increasing FTIT with decreasing N2 (hot start), or by a very slow or zero rate of increase in N2 (hung start). All airstarts were performed with the normal F-15 bleed and accessory loads.

\section{Results and Discussion}

\section{Airplane Performance}

Performance evaluations consisted of intermediate and maximum power aircraft accelerations at altitudes of $5,000,10,000,30,000$, and $40,000 \mathrm{ft}$. A comparison of $40,000-\mathrm{ft}$ accelerations at standard day temperatures and with maximum power is shown in Fig. 5. With one F100 EMD engine and one F100PW-100 engine installed in the F-15 airplane, the time to accelerate at maximum power from Mach 0.8 to Mach 2.0 at $40,000 \mathrm{ft}$ was reduced by 7.4 percent compared to the time with two F100-PW-100 engines installed in the aircraft. The acceleration time for two F100 EMD engines was 23 percent faster than with two F100-PW-100 engines.

With two F100 EMD englines installed, the sustained intermediate power Mach number at 40,000 ft was 1.15 (shown in Fig. 6). Inflight thrust for the EMD engines was calculated in real time. ${ }^{8}$ Data points are shown for every $10 \mathrm{sec}$. Acceleration to Mach 1.0 was rapid, was somewhat slower to Mach 1.1 , and required almost $60 \mathrm{sec}$ from Mach 1.1 to Mach 1.15 .

\section{Augmentor Performance}

Since the augmentor of the F100 EMD engine is significantly different than the standard F100 
engine, an evaluation of the transient capability was conducted at many points in the flight envelope. A time history of a typical idle-tomaximum power throttle transient, at an altitude of $30,000 \mathrm{ft}$ and an airspeed of 225 knots, is shown in Fig. 7. parameters shown are the augmentor segment request, the nozzle area $(\mathrm{AJ})$, the augmentor static pressure (PAB), and the LOD output. The throttle was advanced to maximum power at time $(t)=0$ sec, and the effect of the rotor spoolup can be seen in $\mathrm{PAB}$. At $t=2.7 \mathrm{sec}$, the conditions for augmentor initiation were met and segment. 1 fuel flow was turned on. The LOD output indicated a weak flame until $t=4.5 \mathrm{sec}$, and then indicated a strong flame. The DEEC logic held the segment sequencing for 1 sec after a strong flame had been detected and then requested the succeeding segments. The nozzle area increased in small steps as each new segment was turned on. The $\mathrm{PAB}$ trace showed no large spikes in pressure during the sequencing. The last segment used at this flight condition was segment 14; the other segments were not used to avoid augmentor rumble.

The weak flame seen during the segment 1 lighting was observed during altitude facility testing, and a spray ring modification was developed. As shown in Fig. 8, the modification was done to change the injection of the segment 1 fuel from 90-deg injection (the upper part of the figure) to a direct centerline injection (the lower part of the figure). Also shown is the LOD time history for a typical augmentor transient. The centerline injection showed an immediate indication of a strong flame, whereas the 90-deg injection showed the same weak flame indication seen in Fig 7 .

A summary of the augmentor transient success for intermediate-to-maximum transients is shown in Fig. 9. These transients were performed first with the 90-deg segment 1 fuel injection; many of the tests were repeated with the centerline fuel injection. All of the tests were successful except for a failure to light with the 90-deg injection at 150 knots and $50,000 \mathrm{ft}$. This condition was not tested with the centerline fuel injection because of an airplane problem that prevented completing the augmentor evaluation. For the first flight test of a new augmentor fuel system, this is considered very successful and comparable to the DEEC/F100.9 Future flights will determine the augmentor capability up to $60,000 \mathrm{ft}$.

\section{Airstarts}

The airstart capability of the F100 EMD engine in the F-15 airplane was determined over the airstart envelope. Initial results using the F100 EMD DEEC logic 4.2.1 were very similar to that obtained from the F100 DEEC tests. 4 In the second part of the F100 EMD tests, the revised airstart logic in F100 EMD DEEC logic 4.2.2 was evaluated. This logic increased the requested acceleration rate and resulted in higher fuel flows and faster airstarts. A comparison of airstarts with the two sets of DEEC logic is shown in Fig. 10 for 40-percent spooldown airstarts at an altitude of $25,000 \mathrm{ft}$. The modified logic results in airstarts that are 30 to 50 percent faster.

Because the modified airstart logic increases the starting fuel flow, airstarts can be made at lower airspeeds. Fig. 11 compares the airstart envelope for the original 4.2.1 logic and the modified 4.2.2 logic. Below altitudes of $30,000 \mathrm{ft}$, the modified logic allowed successful airstarts at 175 knots, whereas the original logic was unsuccessful because of hung starts. Above $30,000 \mathrm{ft}$, the modified airstart logic resulted in some hot starts caused by the higher fuel flows.

\section{Throttle Response}

Throttle response of the F100 EMD engine was evaluated for formation flying and aerial refueling capability. The flight condition of $10,000 \mathrm{ft}$ and 400 knots was selected as representative of a tactical situation. The task was formation flying on the lead aircraft for perturbed and nonperturbed conditions and modest manuevering. At this flight condition, formation flying for even nonperturbed tasks received a Cooper-Harper pilot rating of 6 to 8 indicating major deficiencies. A flight condition of $25,000 \mathrm{ft}$ and 300 knots was selected as representative of aerial refueling. Again, large lags or delays were evident between throttle and thrust responses (shown in Fig. 12). Thrust response lags the throttle response by nearly $180 \mathrm{deg}$. The excessively slow response was caused by $\log i c$ in the DEEC that was designed to increase the compressor stall margin during bodie throttle transients. A software change was incorporated into the DEEC which improved the throttle response, and subsequent cooper-Harper ratings of 3 to 4 (minor deficiencies) were obtained for the same flying tasks.

\section{Compressor stalls}

Although the F100 EMD transient operation was very successful for an initial flight evaluation, some compressor stalls did occur during throttle transients to idle in the extreme upper left-hand corner of the flight envelope. The stalls occurred at altitudes above $40,000 \mathrm{ft}$ for airspeeds below 160 knots. The stalls occurred in the compressor and were not predicted by analysis or previous altitude facility tests. Inlet distortion measured by the PT2 probes did not show values high enough to cause stalls. Tests were conducted on an F100 EMD engine in the NASA Lewis Research Center altitude facility specifically to try to duplicate the flight results; the engine would not stall. Later tests were conducted on another F100 EMD engine at the U.S. Air Force Arnold Engineering and Development Center and again, the engine stalls could not be duplicated. Control logic changes to increase the stall margin are being developed.

\section{DEEC Performance}

The DEEC logic, developed for the F100-PW-100, was modified for the F100 EMD. The closed-loop logic operated successfully on the new engine with a minimum of changes. The DEEC flexibility was demonstrated when operability problems were solved by control logic changes.

\section{Future plans}

Future flight tests of the F100 EMD plan for augmentor testing at altitudes up to $60,000 \mathrm{ft}$. The engine stall problem would then be investigated with the installation of additional instrumentation in the engine and modified control logic in the DEEC. Additional testing will be performed to measure inlet total pressure and recovery. 
There are also plans to integrate the engine control system to the flight control system. A program called highly integrated digital electronic control (HIDEC) is investigating the benefits that result from integration of the DEEC system with the airplane systems. 10

\section{Concluding Remarks}

A 17-flight evaluation of the F100 EMD engine in an F-15 airplane was accomplished. The F100 EMD engine has a bigger fan, a higher temperature turbine, a digital control system, and a 16-segment augmentor, all resulting in a 15- to 20-percent increase in thrust. F-15 aircraft acceleration times were improved by 23 percent and nonaugmented maximum airspeed was Mach 1.15.

Augmentor transient throttle performance was evaluated in almost 300 tests. The intermediateto-maximum transients were successful down to 175 knots at $50,000 \mathrm{ft}$.

Two airstart software logic releases were evaluated. A 50-percent improvement in airstart time was obtained with the latest software release.

Initial throttle response was poor and subsequently received a Cooper-Harper pilot rating of 6 to 8. A software change to the DEEC resulted in pilot ratings of 3 to 4 .

The DEEC system was found to be a flexible system capable of rapid software changes to improve engine performance.

\section{References}

${ }^{1}$ Burcham, Frank W., Jr., Myers, Lawrence P. and Walsh, Kevin R., "Flight Evaluation Results for a Digital Electronic Engine Control in an F-15 Airplane," AIAA Paper 83-2703, Nov. 1983.

${ }^{2}$ Myers, Lawrence P., "F-15 Digital Electronic Engine Control system Description," Digital Electronic Engine Control (DEEC) Flight Evaluation in an F-15 Airplane, NASA CP-2298, Paper 3, 1984, pp. 33-53.
${ }^{3}$ Hughes, Donald L., and Mackall, Karen G., "Effects of Inlet Distortion on a static Pressure probe Mounted on the Engine Hub in an F-15 Airplane," Digital Electronic Engine Control (DEEC) Flight Evaluation in an F-15 Airplane, NASA CP-2298, Paper 5, 1984, pp. 73-89.

${ }^{4}$ Burcham, Frank W., Jr., "Airstart Performance of a Digital Electronic Engine Control system on an F100 Engine," Digital Electronic Engine Control (DEEC) Flight Evaluation in an F-15 Airplane, NASA CP-2298, Paper 8, 1984, pp. 127-139.

${ }^{5}$ Walsh, Kevin R. and Burcham, Frank W., Jr. "Flight Evaluation of a Hydromechanical Backup Control for the Digital Electronic Engine Control System in an F100 Engine," Digital Electronic Engine Control (DEEC) Flight Evaluation in an F-15 Airplane, NASA CP-2298, Paper 9, 1984, pp. 141-156.

${ }^{6}$ Myers, Lawrence P., "Flight Testing the Digital Electronic Engine Control in the F-15 Airplane," Digital Electronic Engine Control (DEEC) Flight Evaluation in an F-15 Airplane, NASA CP-2298, Paper 6, 1984, pp. 91-105.

${ }^{7}$ Myers, Lawrence P., Mackall, Karen G., and Burcham, Frank W., Jr., "Flight Evaluation of a Digital Electronic Engine Control system in an F-15 Airplane," AIAA Paper 82-1080, June 1982.

${ }^{8}$ Ray, Ronald J. and Myers, Lawrence P., "RealTime In-Flight Thrust Calculation on a Digital. Electronic Engine Control-Equipped F100 Engine in an F-15 Airplane," Digital Electronic Engine Control (DEEC) Flight Evaluation in an F-15 Airplane, NASA CP-2298, Paper 13, 1984, pp. 215-230.

${ }^{9}$ Burcham, Frank W., Jr. and Pai, David G., "Augmentor Transient Capability of an F100 Engine Equipped with a Digital Electronic Engine Control," Digital Electronic Engine Control (DEEC) Flight Evaluation in an F-15 Airplane, NASA CP-2298, paper 11, 1984, pp. 171-199.

10 Burcham, Frank w., Jr., and Haering, Edward A., Jr., "Highly Integrated Digital Engine Control system on an F-15 Airplane, AIAA Paper 84-1259, June 1984.

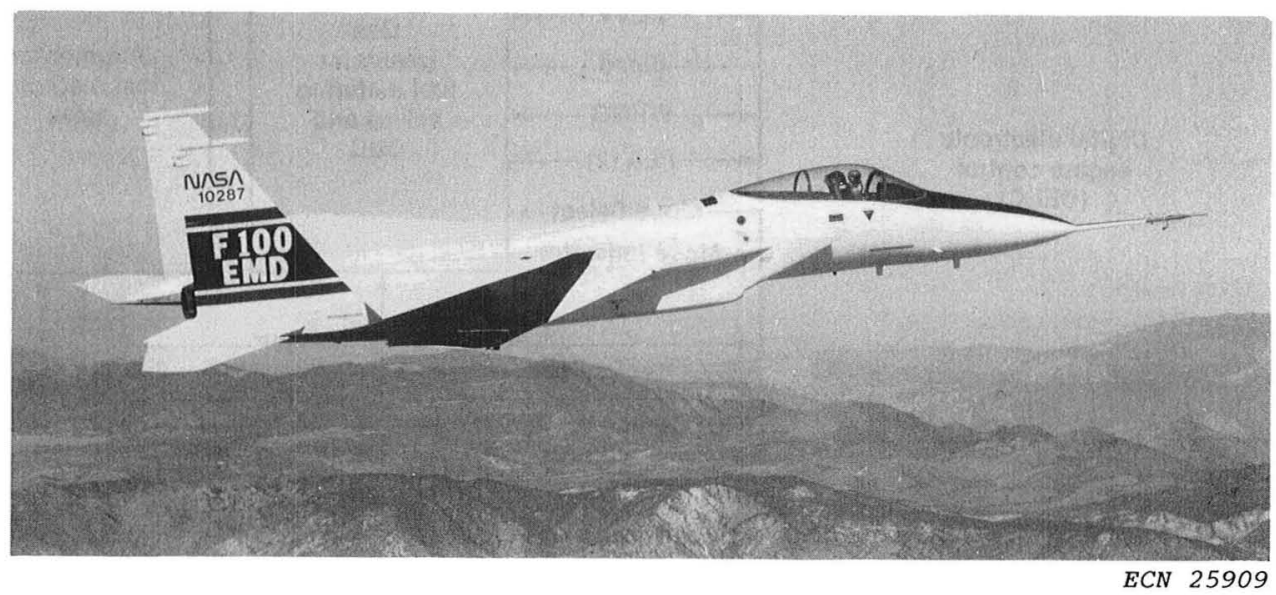

Fig. 1 The F-15 airplane that was used for the F100 EMD evaluation. 


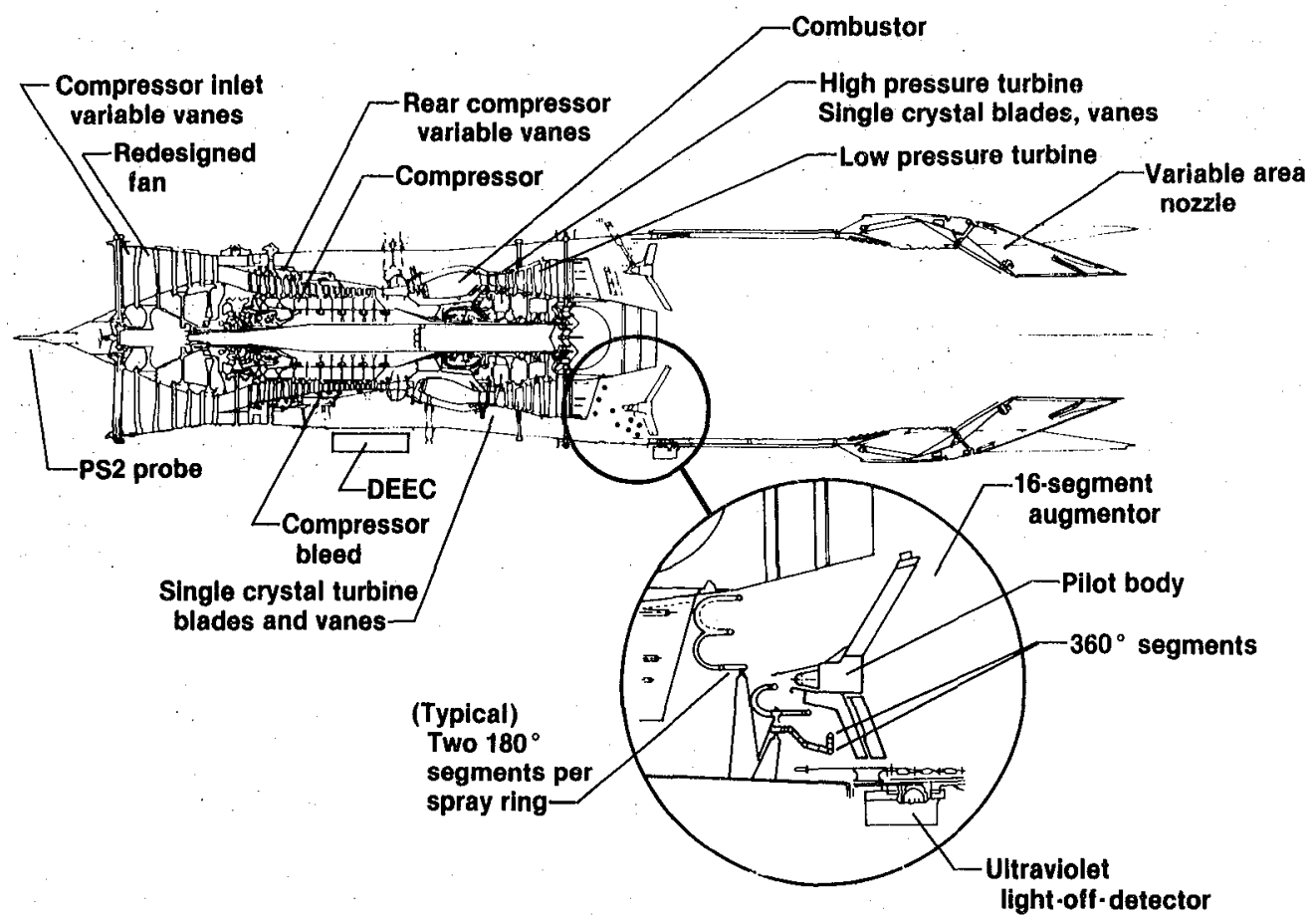

Fig. 2 Cutaway view of the FlOO EMD engine showing advanced features.

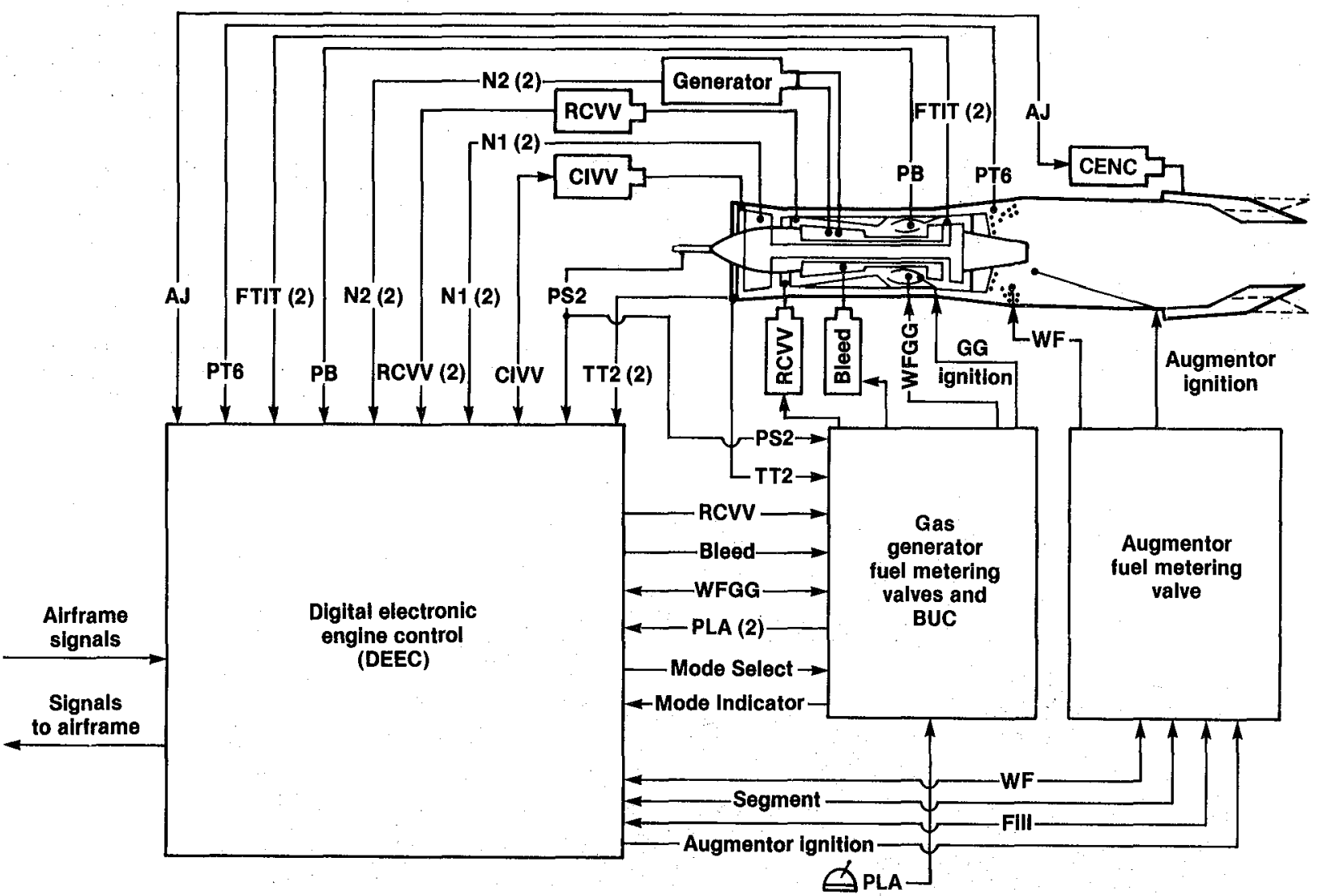

Fig. 3 The DEEC system that was used on the F100 EMD engine. 


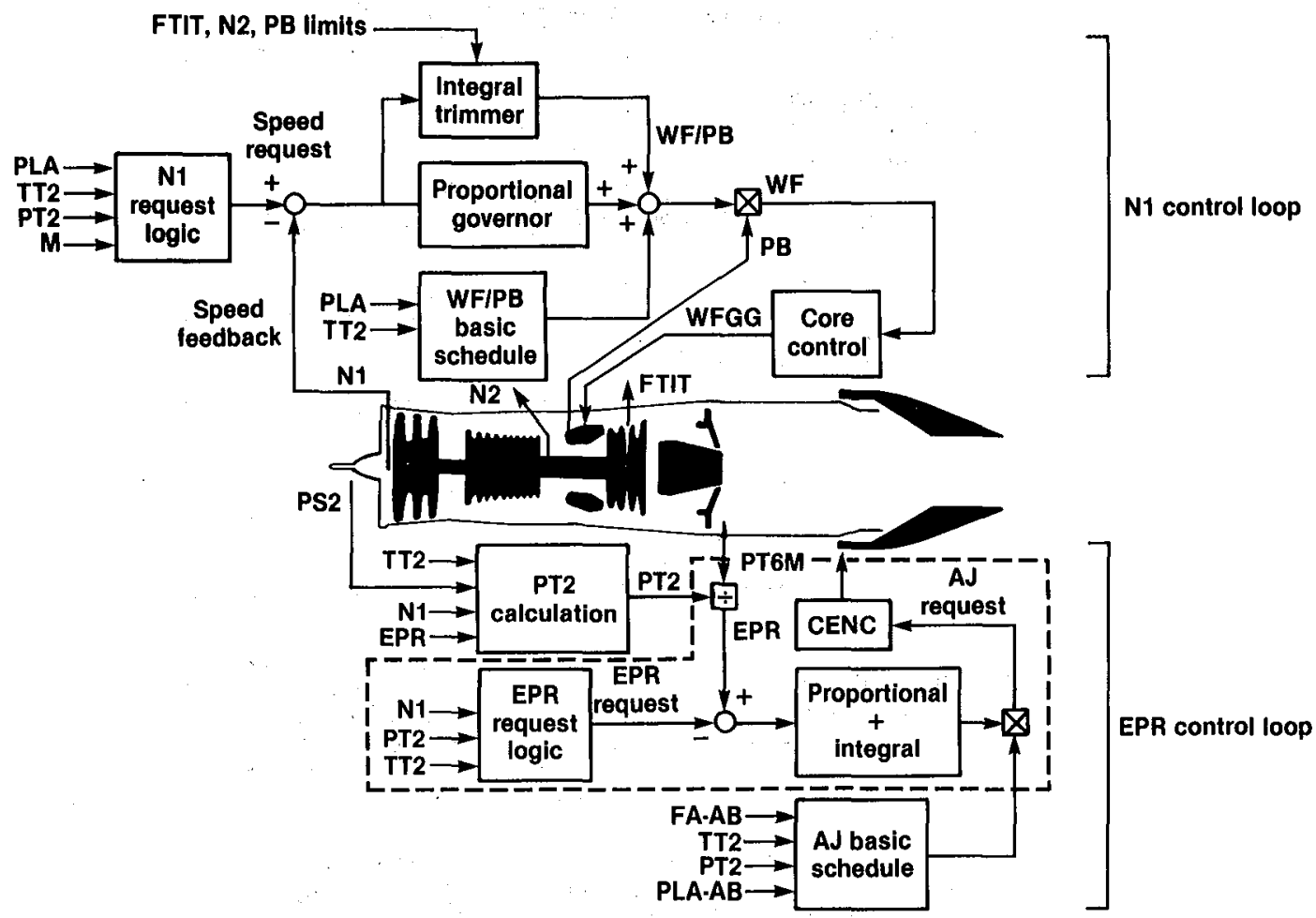

Fig. 4 The DEEC modes for fan rotor speed and engine pressure ratio.

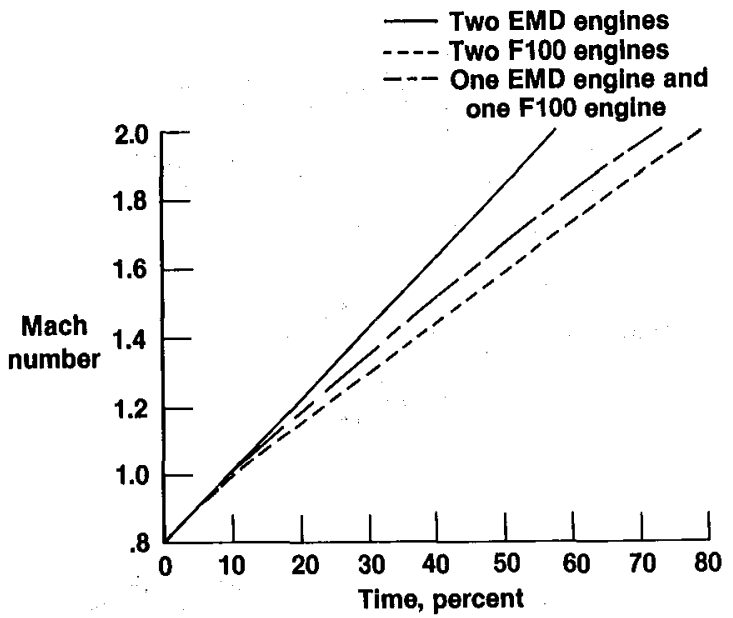

Fig. 5 A comparison of 40,000-ft level accelerations at maximum power and standard day conditions.

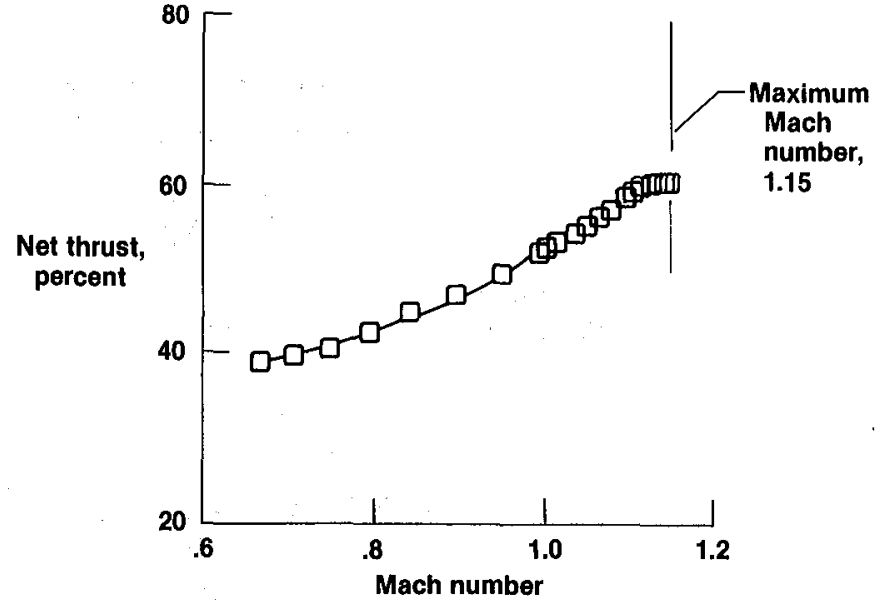

Fig. 6 A 40,000-ft acceleration at intermediate power and standard day conditions with two F100 EMD engines installed on the F-15 airplane. 

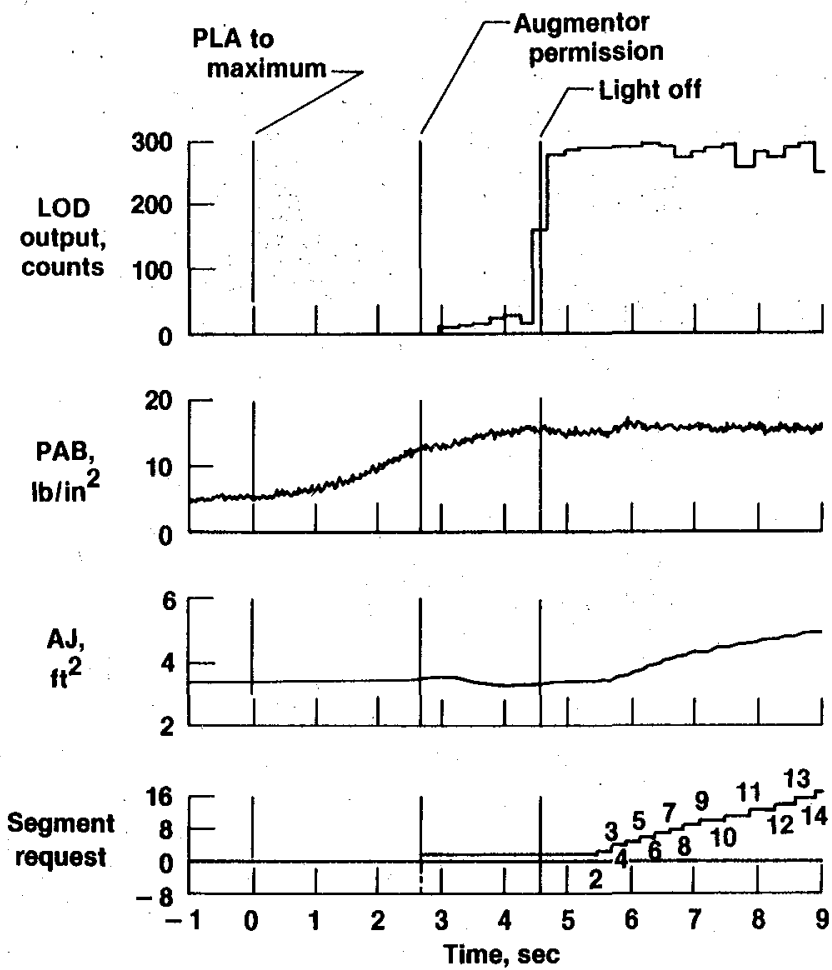

Fig. 7 A time history of idle-to-maximum power throttle transient at an altitude of $30,000 \mathrm{ft}$ and an airspeed of 225 knots; one F100 EMD engine with a 16-segment augmentor and a $90^{\circ}$ pilot spray ring injection.
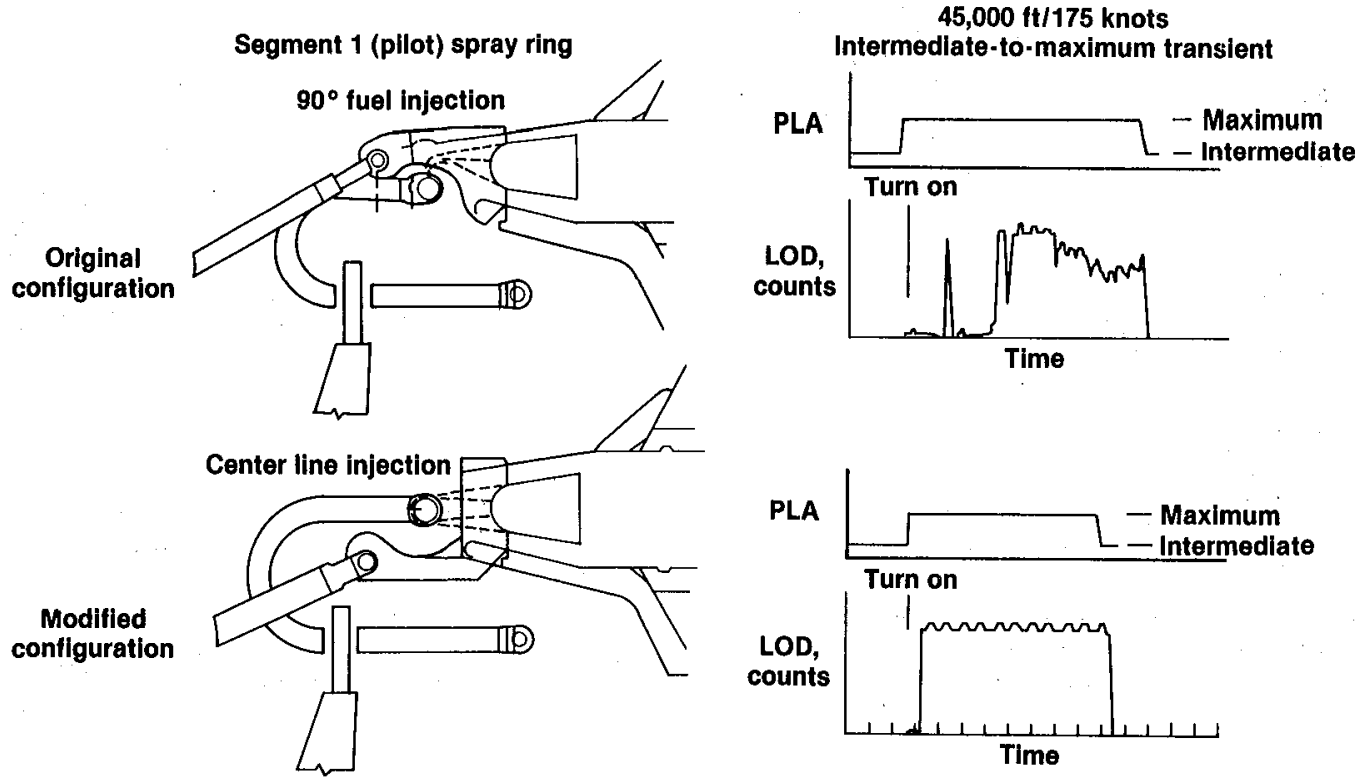

Fig. 8 Effects of spray ring modification on augmentor performance. 
Segment 1 spray ring

$\checkmark$ Original $90^{\circ}$ injection

- Modifled centerline injection

Open symbols denote successful transients

Solid symbol denotes transients

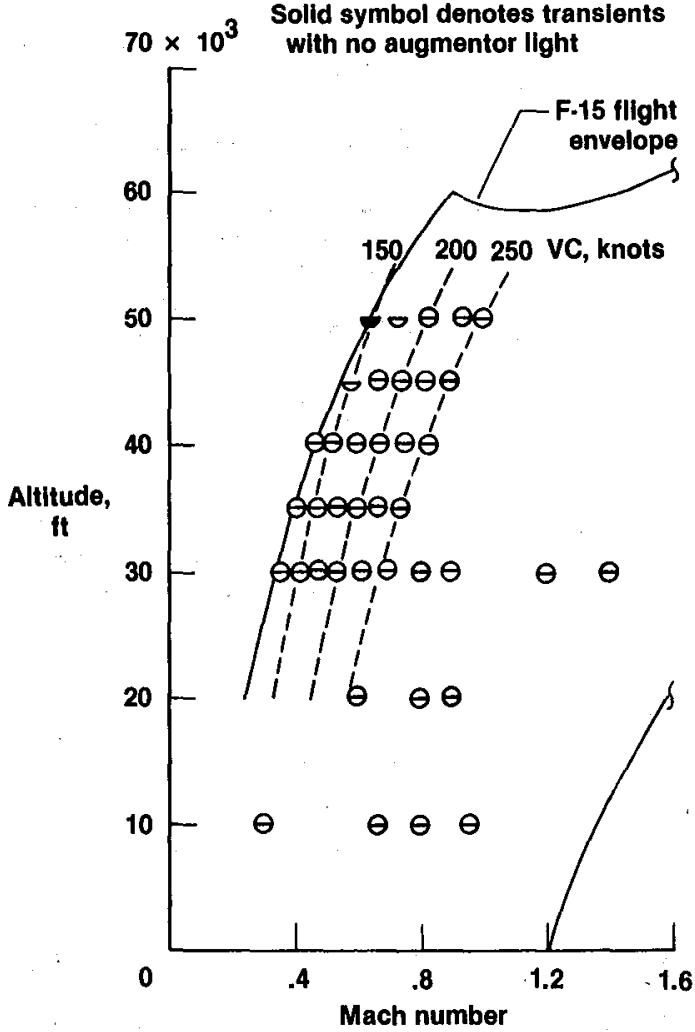

Fig. 9 A sumiary of F 100 EMD

intermediate-to-maximum throttle transients.

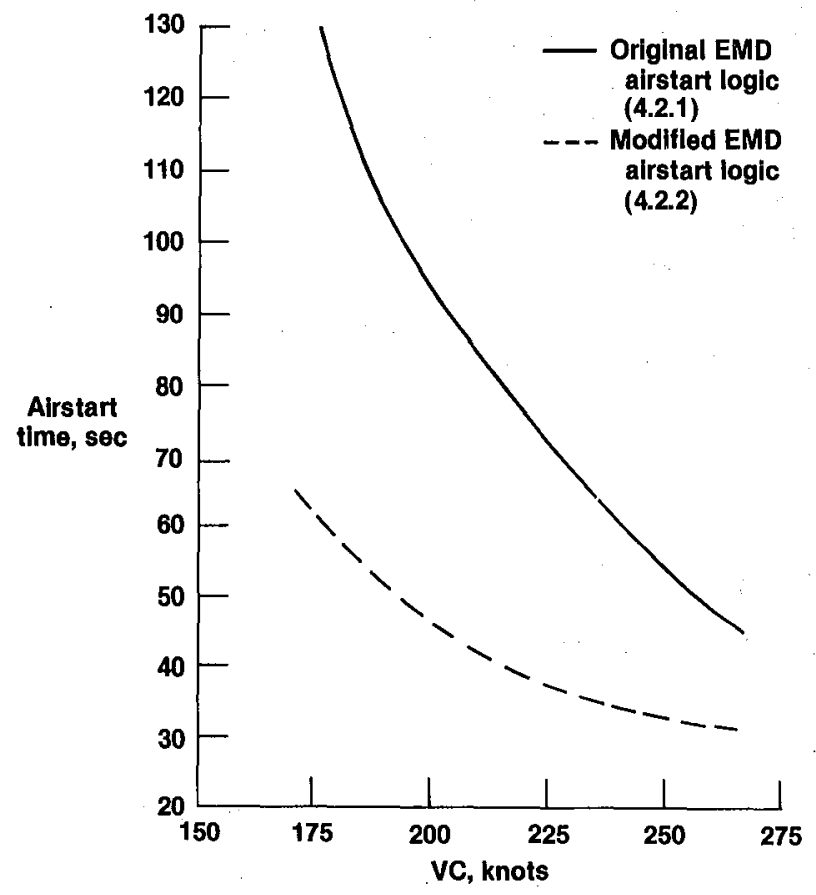

Fig. 10 A comparison of airstart times for the original and modified F100 EMD airstart logic for 40-percent spooldown airstarts at an altitude of $25,000 \mathrm{ft}$.
Success boundary

- Original EMD airstart logic (4.2.1)

- Modified EMD airstart logic (4.2.2)

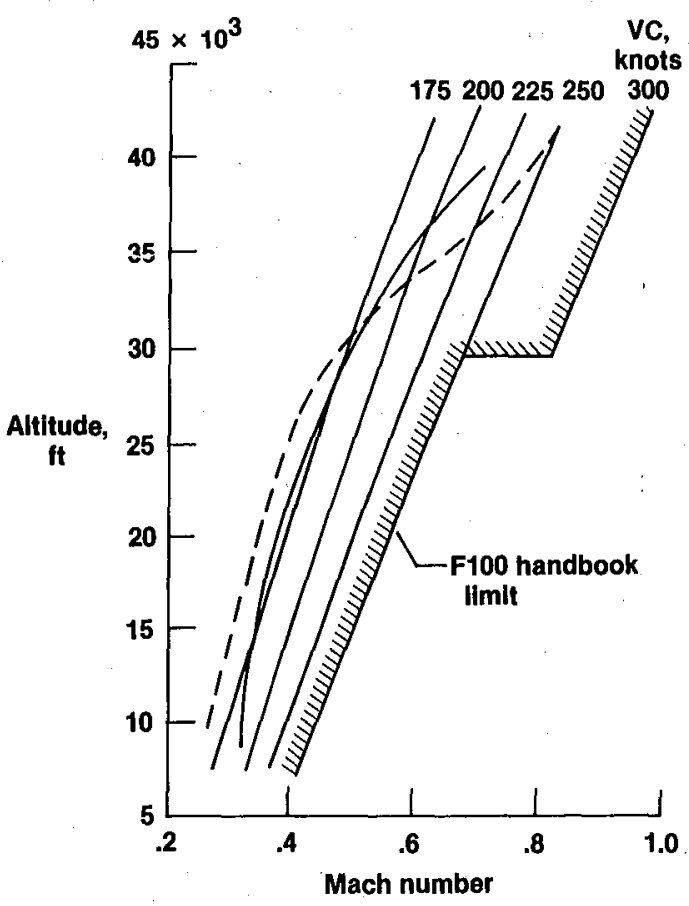

Fig. 11 The effect of an EMD airstart logic modification on the airstart envelope for 40- and 25-percent spooldown airstarts.

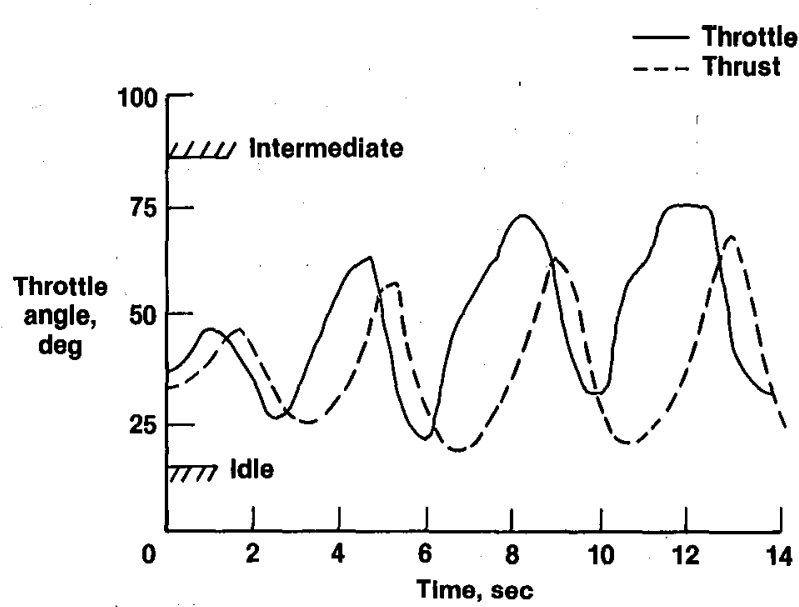

Fig. 12 Thrust response to throttle cycling during close formation flying. 


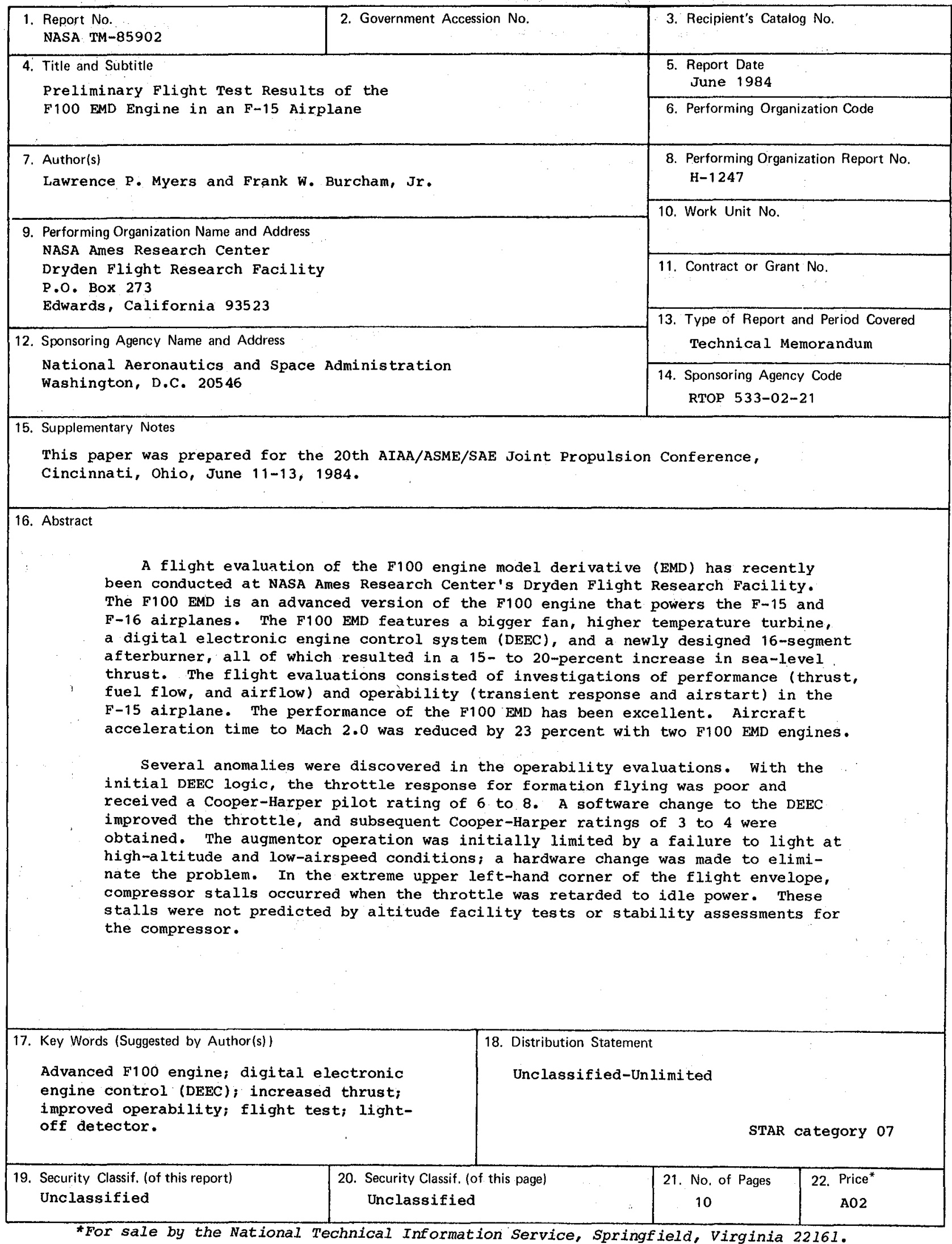


3

$v$ 
